\title{
OUTCOME OF ARTERIOVENOUS FISTULA FOR HAEMODIALYSIS ACCESS
}

\author{
Susan Johny1, Anil Luther ${ }^{2}$
}

${ }_{1}^{1}$ Assistant Professor, Department of General Surgery, Amala Institute of Medical Sciences, Thrissur.

2 Professor, Department of General Surgery, Christian Medical College, Ludhiana.

\begin{abstract}
\section{BACKGROUND}

Vascular access care is a classic example of multidisciplinary team work between nephrologists, vascular surgeons, interventional radiologists, ultrasound technicians and dialysis nurses. The National Kidney Foundation (NFK) began the Dialysis Outcomes and Quality Initiative (DOQI) in 1995, now referred to as the Kidney Disease Outcomes and Quality Initiative (KDOQI), which published a large evidence-based set of clinical guidelines to help improve healthcare outcomes among patients with end-stage renal disease (ESRD).

This study was conducted to determine the outcome of arteriovenous fistulae created for haemodialysis access in Christian Medical College, Ludhiana. All arteriovenous fistulae were created using 6-0 prolene and the patients were followed up for a period of 9 months. The outcome was measured in terms of primary success rate, primary failure rate and complications.
\end{abstract}

\section{MATERIALS AND METHODS}

This study was a one-year retrospective and one-year prospective study conducted in the Department of Surgery and Nephrology, Christian Medical College and Hospital, Ludhiana. After determination of the appropriate limb for surgery, arteriovenous fistulae were done under local anaesthesia in the operation theatre. All anastomosis were end (vein) to side (artery) and were done by using 6-0 prolene. The fistula created was monitored for a good thrill, pulse and any immediate complication such as bleeding or thrombosis. After four to six weeks, a fistula with a good thrill was considered to be mature and was subjected to cannulation and then haemodialysis. The fistula flow rate was recorded at initiation of haemodialysis and after four weeks of haemodialysis. A ninemonth follow-up study was done, and the final outcome of the fistula was measured in terms of duration of successful use, need for creation of a new fistula at another site and need for re-exploration.

\section{RESULTS}

1. At the end of the 9 -month follow-up period, $62.7 \%$ of the AVF had a successful outcome; $21.2 \%$ became non-functional. In $15.3 \%$ cases, a new fistula was made at another site. One case was lost to follow-up.

2. The primary failure rate was $4.2 \%$.

\section{CONCLUSION}

This study has thus demonstrated that the vascular unit of General Surgery in Christian Medical College, Ludhiana, is making arteriovenous access for haemodialysis at a rate comparable to other centres in India and worldwide.

\section{KEYWORDS}

Arteriovenous Fistula, Haemodialysis, Primary Patency, Primary Failure Rate.

HOW TO CITE THIS ARTICLE: Johny S, Luther A. Outcome of arteriovenous fistula for haemodialysis access. J. Evolution Med. Dent. Sci. 2018;7(03):361-366, DOI: 10.14260/jemds/2018/80

\section{BACKGROUND}

Vascular access care is a classic example of multidisciplinary team work between nephrologists, vascular surgeons, interventional radiologists, ultrasound technicians and dialysis nurses. To achieve the best outcome the team must agree on a set of goals, collaborate closely and maintain good mutual communication. A key player in this multidisciplinary approach is a dedicated access coordinator who acts as a liaison officer between the disciplines and schedules of the meetings. The assimilation of recommendations and guidelines into clinical practice is only possible if all parties involved are willing and motivated to

'Financial or Other Competing Interest': None.

Submission 17-12-2017, Peer Review 30-12-2017,

Acceptance 01-01-2018, Published 13-01-2018.

Corresponding Author:

Dr. Susan Johny,

Assistant Professor

Department of General Surgery,

Amala Institute of Medical Sciences, Thrissur.

E-mail: drsusanjohny@gmail.com

DOI: $10.14260 /$ jemds $/ 2018 / 80$ co-operate. In 2003, the United States National Vascular Access Improvement Initiative (NVAII) launched Fistula First. This is a large national initiative that offers a set of tools for physicians and dialysis facilities in order to accelerate increasing AVF use in haemodialysis patients. Eleven change concepts guide the target groups step-by-step to the best practice. In Netherlands, the CIMINO-project (Care Improvement by Multidisciplinary approach for Increase of Native vascular access Obtainment) was initiated as an effort to increase AVF use. ${ }^{1}$

The National Kidney Foundation (NFK) began the Dialysis Outcomes and Quality Initiative (DOQI) in 1995, now referred to as the Kidney Disease Outcomes and Quality Initiative (KDOQI), which published a large evidence-based set of clinical guidelines to help improve healthcare outcomes among patients with end-stage renal disease (ESRD). One major focus of KDOQI is optimal arteriovenous (AV) access management, which has led to the creation of the National Vascular Access Improvement Initiative (NAVII) and its Fistula First campaign. KDOQI makes it clear that all patients with stage IV or stage $\mathrm{V}$ chronic kidney disease (CKD) who opt for haemodialysis should undergo autologous fistula 
creation. In order to preserve viable access sites, they recommend a radiocephalic arteriovenous fistula (RCAVF) as the first and best option. If not feasible, then a brachiocephalic arteriovenous fistula followed by a basilic vein transposition should be created in the non-dominant arm. Prosthetic arteriovenous bridge grafts and tunnelled dialysis catheters are mentioned as last resorts in patients with no autologous options. These recommendations are based upon available data that suggests that AVF have superior patency, fewer complications, require fewer reinterventions and ultimately improve patient survival. ${ }^{2}$

This is a descriptive observational study conducted in the Department of General Surgery of Christian Medical College, Ludhiana. The study is to analyse the outcome of arteriovenous access created for haemodialysis in a specific time period.

\section{MATERIALS AND METHODS}

This study was a one-year retrospective and one-year prospective study conducted in the Department of Surgery and Nephrology, Christian Medical College and Hospital, Ludhiana.

The retrospective group included all the cases of arteriovenous fistulae for haemodialysis access, done from $01 / 11 / 2009$ to $31 / 10 / 2010$. Details were acquired from the patients' medical record. Among these patients those who came for regular haemodialysis to our hospital were followed up for a period of nine months after the initiation of dialysis.

The prospective group included all the arteriovenous fistulae done for haemodialysis access from $01 / 11 / 2010$ to $31 / 10 / 2011$. All patients were personally worked up and followed up in the ward or on OPD basis. After the clinical assessment, the site of fistula was determined and patients were educated about the need for protecting the selected limb from any type of cannulations or injections. In case of inadequacy of vasculature in both the upper limbs, the same was confirmed by a Duplex examination.

After determination of the appropriate limb for surgery, the procedure was done under local anaesthesia in the operation theatre. Intraoperative heparin saline was used in all cases. All arteriovenous anastomosis were end (vein) to side (artery) and were done by using 6-0 prolene. The fistula created was monitored for a good thrill, pulse and any immediate complication such as bleeding or thrombosis. After four to six weeks, a fistula with a good thrill was considered to be mature and was subjected to cannulation and then haemodialysis. The fistula flow rate was recorded at initiation of haemodialysis and after four weeks of haemodialysis.

A nine-month follow-up study was done, which included monitoring of the fistula flow rate after four weeks of initiation of haemodialysis. The final outcome of the fistula at the end of nine-month study was measured in terms of duration of successful use, need for creation of a new fistula at another site or need for re-exploration.

The data was entered in Microsoft Excel. The frequencies, proportions and chi-square test was done using SPSS software version 17 .

\section{Inclusion Criteria}

1. Patients with chronic renal failure who required a permanent haemodialysis access.
2. Patients with chronic renal failure who already had any other type of haemodialysis access, but needed a permanent arteriovenous fistula.

3. Patients with chronic renal failure who had a failed previous arteriovenous access.

\section{Exclusion Criteria}

1. Patients with inadequate peripheral vascular system in both upper limbs. The exclusion was done by clinical assessment and Duplex study.

\section{RESULTS}

A total of 118 arteriovenous fistulae (AVF) were made during the study period, all by experienced surgeons in the vascular unit of the department. All fistulae were made by end-to-side anastomosis with 6-0 or 5-0 prolene sutures. All cases were followed up for a period of 9 months.

\begin{tabular}{|c|c|}
\hline Retrospective Group & 65 \\
\hline Prospective Group & 53 \\
\hline Total No. of AVF & 118 \\
\hline \multicolumn{2}{|c|}{ Table 1. Grouping of Study Population } \\
\hline
\end{tabular}

Out of the total number of AVF, 65 belonged to the retrospective group and 53 belonged to the prospective group.

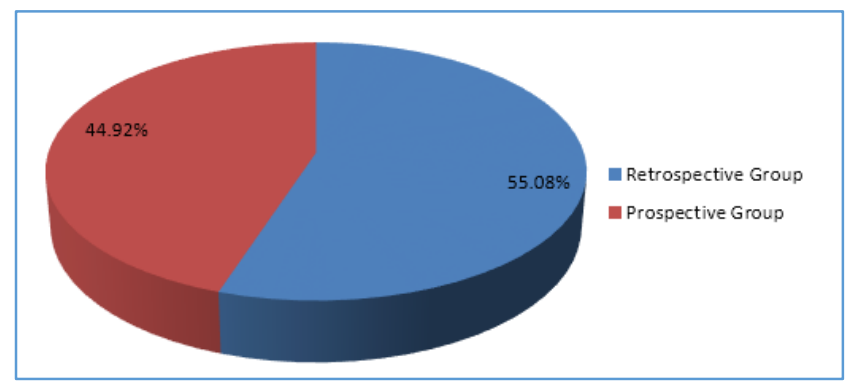

Figure 1. Grouping of Study Population

\begin{tabular}{|c|c|c|}
\hline Diagnosis & No. & \% \\
\hline Chronic Kidney Disease (CKD)- Stage V & 103 & $87.3 \%$ \\
\hline CKD- Stage IV & 4 & $3.38 \%$ \\
\hline Obstructive Uropathy & 3 & $2.54 \%$ \\
\hline CKD- Stage III & 2 & $1.69 \%$ \\
\hline Wegener's Granulomatosis & 2 & $1.69 \%$ \\
\hline Polycystic Kidney Disease & 2 & $1.69 \%$ \\
\hline Post Renal Transplant Kidney Failure & 2 & $1.69 \%$ \\
\hline \multicolumn{2}{|c|}{ Total } & $\mathbf{1 1 8} \%$ \\
\hline Table 2. Diagnosis of the Study Population \\
\hline
\end{tabular}

Out of the 118 AVF made, 103 (87.3\%) was for patients with the diagnosis of Chronic Kidney Disease- Stage V.

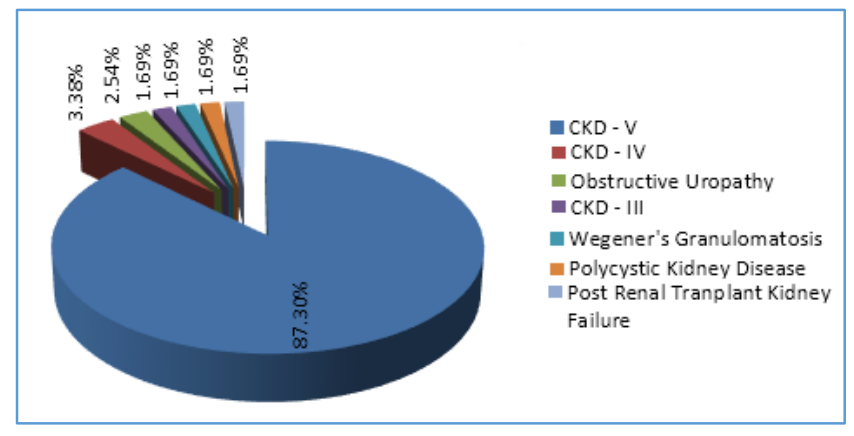

Figure 2. Diagnosis of the Study Population 


\begin{tabular}{|c|c|c|}
\hline Comorbid Illness & No. & $\mathbf{\%}$ \\
\hline Diabetes Mellitus Type 2 & 51 & $43.2 \%$ \\
\hline Systemic Hypertension & 87 & $73.7 \%$ \\
\hline Coronary Artery Disease & 11 & $9.32 \%$ \\
\hline Respiratory Disease & 1 & $0.8 \%$ \\
\hline Congestive Cardiac Failure & 2 & $1.7 \%$ \\
\hline DM Type 2 + Systemic Hypertension & 35 & $29.7 \%$ \\
\hline $\begin{array}{c}\text { DM Type 2 + Systemic Hypertension } \\
\text { + CAD }\end{array}$ & 5 & $4.2 \%$ \\
\hline Systemic Hypertension + CAD & 5 & $4.2 \%$ \\
\hline DM Type 2 + CAD & 1 & $0.8 \%$ \\
\hline HIV Positive & 0 & $0 \%$ \\
\hline HCV Positive & 9 & $7.6 \%$ \\
\hline HBsAg Positive & 1 & $0.8 \%$ \\
\hline Others & 7 & $5.9 \%$ \\
\hline None & 10 & $8.5 \%$ \\
\hline Table 3. Comorbidities in the Study Population \\
\hline \multicolumn{2}{|c|}{}
\end{tabular}

The most common co-morbidity was found to be Systemic Hypertension (73.7\%). 43.2\% of the population had Diabetes Mellitus Type 2. Out of the total study population, $29.7 \%$ was found to have co-existing Systemic Hypertension and Diabetes Mellitus.

There was a statistically significant increase in the number of late complications in patients who had Systemic Hypertension, Diabetes Mellitus Type 2 and in patients who had both the co-morbidities co-existing ( $\mathrm{p}$ value 0.000 , chisquare test applied).

9 cases were $\mathrm{HCV}$ positive and 1 was HBsAg positive. There were no HIV positive cases in the study population.

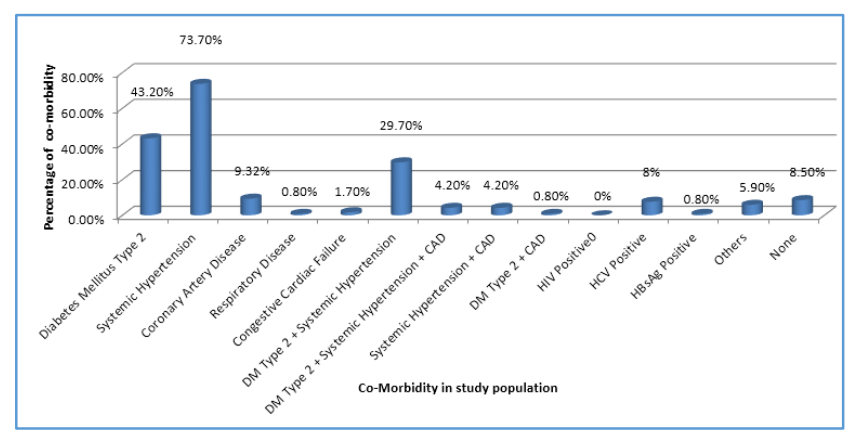

Figure 3. Co-Morbidities in the Study Population

\begin{tabular}{|c|c|c|}
\hline Past History & No. & $\%$ \\
\hline Bleeding Diathesis & 1 & $0.8 \%$ \\
\hline Use of Anticoagulants & 1 & $0.8 \%$ \\
\hline Previous AVF & 10 & $8.47 \%$ \\
\hline IV Cannulation of Upper Limb Veins & 2 & $1.7 \%$ \\
\hline IV Cannulation + IJV insertion & 104 & $88.1 \%$ \\
\hline IV Cannulation + IJV insertion + Previous AVF & 8 & $6.8 \%$ \\
\hline Smoking & 5 & $4.2 \%$ \\
\hline Anaemia & 84 & $71.2 \%$ \\
\hline Peripheral Vascular Disease & 0 & $0 \%$ \\
\hline
\end{tabular}

A statistically significant correlation was found between the past history of IV cannulation and IJV insertion with late complications of AVF ( $p$ value- 0.000). However, there was no statistically significant correlation between anaemia and late complications of AVF (p value- 0.160 ).

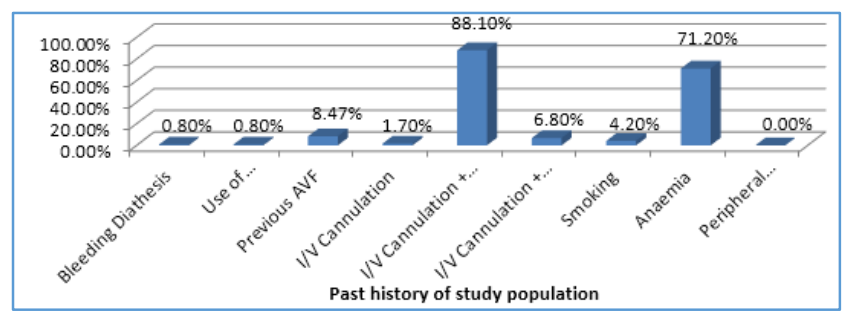

Figure 4. Past History of Study Population

\begin{tabular}{|c|c|c|}
\hline Type of Fistula & No, & $\%$ \\
\hline Left Radiocephalic & 52 & $44.1 \%$ \\
\hline Left Brachiocephalic & 44 & $37.3 \%$ \\
\hline Right Radiocephalic & 11 & $9.3 \%$ \\
\hline Right Brachiocephalic & 8 & $6.8 \%$ \\
\hline Left Brachiobasilic & 1 & $0.8 \%$ \\
\hline Right Brachiobasilic & 1 & $0.8 \%$ \\
\hline Left Brachiocubital & 1 & $0.8 \%$ \\
\hline Total & 118 & $100 \%$ \\
\hline
\end{tabular}

The most common type of AVF made was the Left Radiocephalic fistula (44.1\%). This was followed by the Left Brachiocephalic fistula (37.3\%). This predominance of leftsided fistulae in the population was due to the fact that left was the non-dominant limb in all cases in the study population.

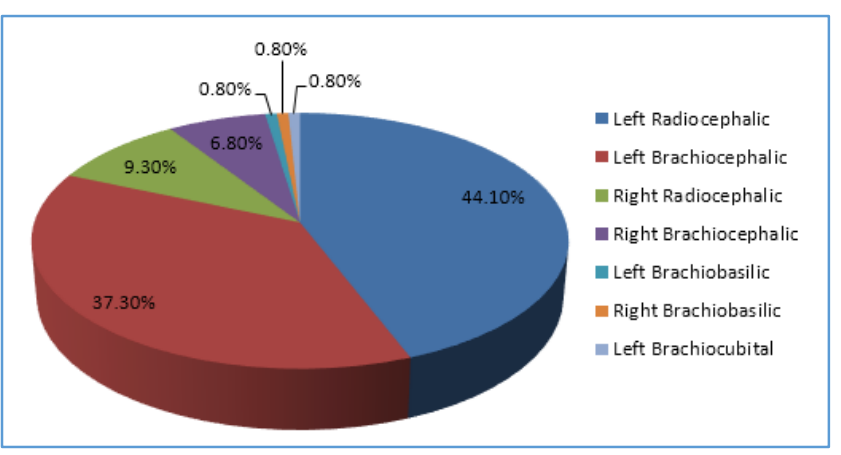

Figure 5. Type of Arteriovenous Fistula

\begin{tabular}{|c|c|c|}
\hline Immediate Postoperative Evaluation & No. & $\mathbf{\%}$ \\
\hline Good Thrill & 115 & $97.5 \%$ \\
\hline Good Pulse & 3 & $2.5 \%$ \\
\hline
\end{tabular}

Table 6. Immediate Postoperative Pulse and Thrill

$97.5 \%$ of cases (115 out of 118) demonstrated a good thrill in the immediate postoperative period. $2.5 \%$ (3 out of 118) had only demonstrable pulse.

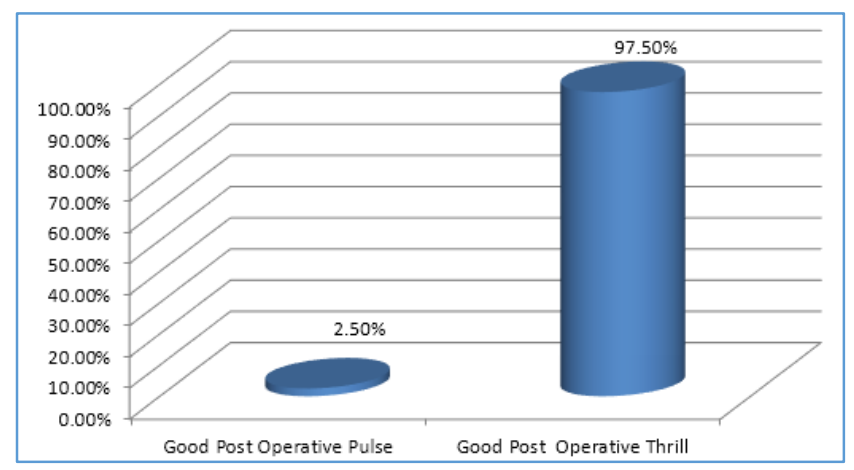

Figure 6. Postoperative Pulse and Thrill 


\begin{tabular}{|c|c|c|}
\hline Early Re-Exploration & No. & \% \\
\hline Fistula working post exploration & 10 & $8.5 \%$ \\
\hline Fistula not working post exploration & 5 & $4.2 \%$ \\
\hline Total & $\mathbf{1 5}$ & $\mathbf{1 2 . 7 \%}$ \\
\hline \multicolumn{2}{|c|}{ Table 7. Early Re-Exploration of AVF } \\
\hline
\end{tabular}

Out of the 15 AVFs requiring re-exploration before maturation, 10 were done for thrombus at the anastomotic site. Thrombectomy was done and 6 of them started working.

The rest of the 5 re-explorations were done for wound haematoma. The haematoma was removed, the anastomotic leak was repaired and 4 of them started working again. The primary failure rate, i.e. the total number of fistulae in the study population which failed before maturation was $4.2 \%$.

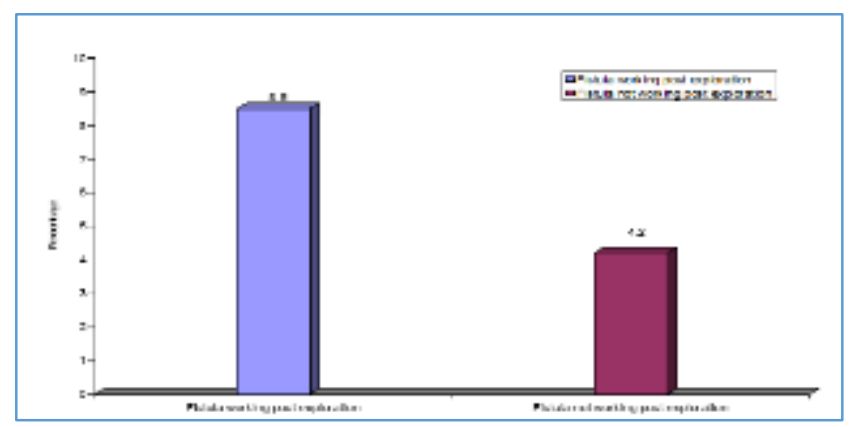

Figure 7. Primary Failure Rate of AVF

\begin{tabular}{|c|c|}
\hline Procedure & Number \\
\hline Saphenous Vein Interposition Graft & 5 \\
\hline Transposition of Brachiocephalic Fistula & 6 \\
\hline Ulno-basilic Saphenous Interposition Graft & 1 \\
\hline \multicolumn{2}{|c|}{ Table 8. Late Re-Exploration } \\
\hline
\end{tabular}

Late re-exploration was done for 19 AVFs. Out of these 19, 4 of them required creation of new fistula at another site. 3 of them remained non-functional even after the re-exploration. Ulno-basilic interposition graft with saphenous vein was put for one case. Saphenous interposition graft was put for 5 radiocephalic fistulae during their re-exploration. Transposition of brachiocephalic fistulae were done in 6 cases.

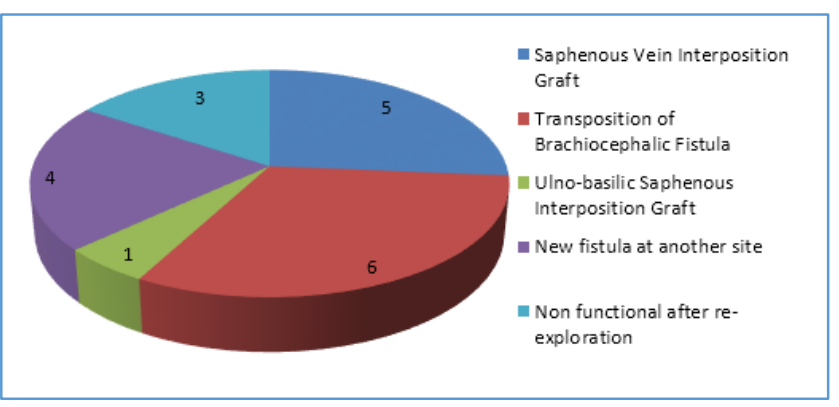

Figure 8. Late Re-Exploration of AVF

\begin{tabular}{|c|c|c|}
\hline Duration & No. & \% \\
\hline 1- 2.9 months & 100 & $84.74 \%$ \\
\hline 3- 5.9 months & 82 & $69.4 \%$ \\
\hline 6- 9 months & 74 & $62.7 \%$ \\
\hline \multicolumn{2}{|c|}{ Table 9. Duration of Successful Use of AVF } \\
\hline
\end{tabular}

$84.74 \%$ of the AVFs were used successfully for a minimum time period of 1 to 2.9 months. $69.4 \%$ were used for the time period of 3 to 5.9 months and $62.7 \%$ were used for 6 to 9 months.

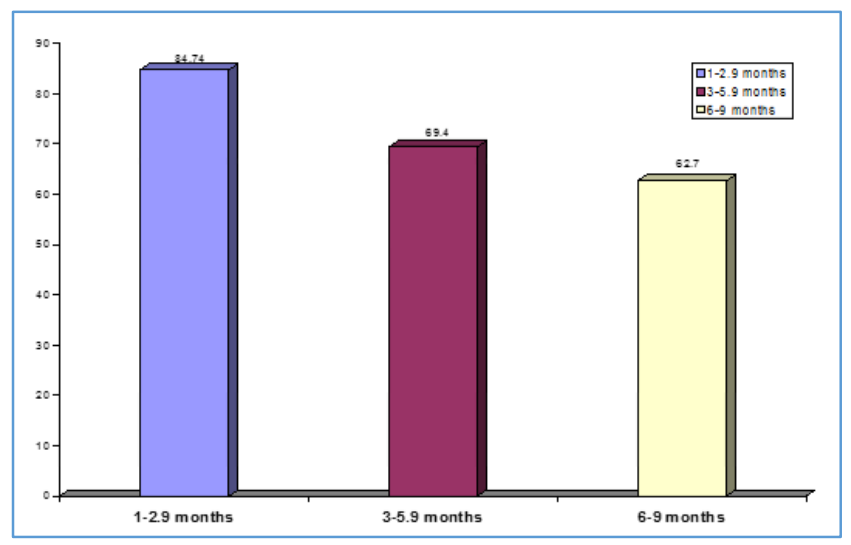

Figure 9. Duration of Successful Use of AVF

\begin{tabular}{|c|c|c|}
\hline Outcome & No. & \% \\
\hline Successful Fistula & 74 & $62.7 \%$ \\
\hline Non-Functional Fistula & 25 & $21.2 \%$ \\
\hline New Fistula made at another site & 18 & $15.3 \%$ \\
\hline Lost to follow-up & 1 & $0.8 \%$ \\
\hline Total & $\mathbf{1 1 8}$ & $\mathbf{1 0 0} \%$ \\
\hline Table 10. Outcome of AVF \\
\hline
\end{tabular}

The total number of AVFs that were functioning successfully at the end of the 9-month follow-up period was 74 (62.7\%); 25 became non-functional and in 18 cases a new fistula had to be made at another site. One case was lost to follow-up.

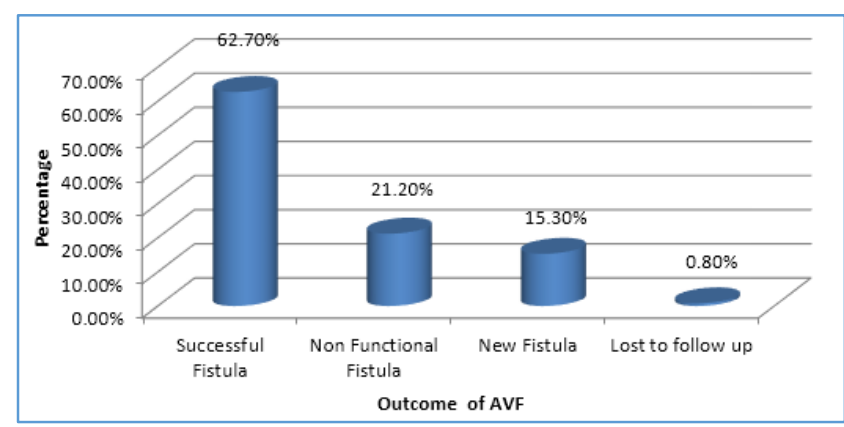

Figure 10. Outcome of AVF

\section{DISCUSSION}

Access to the vascular system is necessary in patients with chronic renal failure planned to undergo dialysis. The gold standard for chronic dialysis has become the native arteriovenous fistula (AVF) since 1966 when Brescia and associates constructed a fistula between the radial artery and the cephalic vein. ${ }^{3}$

This study was conducted in the Department of General Surgery and Nephrology, Christian Medical College and Hospital, Ludhiana to observe the outcome of AVFs made in the department from the period of $1^{\text {st }}$ November 2009 to $31^{\text {st }}$ October 2011. All the AVFs made from 1st November 2009 to $31^{\text {st }}$ October 2010 were studied retrospectively, whereas 
fistulae made between the time period from $1^{\text {st }}$ November 2010 to $31^{\text {st }}$ October 2011 were studied prospectively. All cases were followed up for a period of nine months as per protocol.

There were a total of 118 AVF made in the study period. Out of this study population, $65(55.08 \%)$ belonged to the retrospective group and 53 (44.92\%) belonged to the prospective group.

In this study, $87.3 \%$ of the AVF were made in patients with Chronic Kidney Disease (CKD)- stage V; $3.38 \%$ of the study population was in CKD IV stage and $1.69 \%$ in stage III. A small amount of population had Obstructive Uropathy (2.54\%), Wegener's Granulomatosis (1.69\%) and Polycystic Kidney (1.69\%) as the cause of End-Stage Renal Disease. In a single centre study, clinical and epidemiological data obtained from Shanghai First People's Hospital Affiliated to Jiaotong University, 376 patients were included, all undergoing haemodialysis through a native arteriovenous fistula. The most common cause of renal failure in this study population was chronic glomerulonephritis (68.62\%). ${ }^{4}$ In another study by Kazemzadeh GH et al published in 2012, diseases detected in $10.6 \%$ of patients included glomerulonephritis, polycystic kidney, uropathy, pyelonephritis and lupus erythematosus. 5

In a study conducted in Brazil in 2008, 154 out of 219 patients (86\%) with arteriovenous access had hypertension as a pre-existing co-morbidity. ${ }^{6}$ These results are comparable to the present study, emphasising the prevalence of systemic hypertension in renal failure patients undergoing haemodialysis.

Central vein stenosis can jeopardise the future of arteriovenous fistula and arteriovenous graft in the ipsilateral extremity. Occurrence of central vein stenosis in association with indwelling intravascular devices including short-term, small-diameter catheters such as peripherally inserted central catheters, long-term haemodialysis catheters as well as pacemaker wires has been recognised for over two decades. Endothelial injury with subsequent changes in the vessel wall results in development of microthrombi, smooth muscle proliferation and central vein stenosis. ${ }^{7}$

To evaluate the impact of central venous obstruction on upper extremity haemodialysis access failure, a retrospective study was done by Criado E et al in 1994. This study reviewed 158 upper extremity haemodialysis access procedures performed in 122 patients during a 1-year period in the Division of Vascular Surgery, University of North Carolina at Chapel Hill School of Medicine. Fourteen (11.5\%) patients had central vein obstruction as the cause of severe arm swelling, graft thrombosis or graft malfunction. All 14 patients had bilateral temporary subclavian vein dialysis catheters and failed upper extremity arteriovenous access. ${ }^{8}$ In the present study only 2 cases of subclavian vein stenosis were reported, of which both had previous history of cannulation of subclavian vein.

Only $4.2 \%(5 / 118)$ of the population were smokers. Hence, no significant correlation of smoking with the outcome of AVF, whereas studies have shown smoking to be a risk factor for access failure. A study was published by Mauricio Monroy-Cuadras et al in 2010, in which history of smoking (OR 4.3, P $<0.001$ ), was independently associated with loss of primary patency. ${ }^{9}$ This variation in our study group is due to the fact that most of the patients belong to the
Sikh community where smoking is a religious taboo. Out of the total $97.5 \%$ of cases (115 out of 118) demonstrated a good thrill in the immediate post-operative period, whereas $2.5 \%$ ( 3 out of 118 ) had only demonstrable pulse.

In a study published by Kazemzadeh GH et al in 2012, 245 patients were included in a program for the first time AVF access from 22 November 2005 to 22 November 2006. Most of the fistulae had appropriate functions (good pulse or thrill) immediately after the operation (83.7\%), 5.7\% had poor function and $1.2 \%$ showed no function. 5

Out of the 15 arteriovenous fistulae which required exploration before maturation 10 worked after the exploration, whereas 5 did not work post exploration. This gives the primary failure rate of AVF in the study population, i.e. $4.2 \%$.

In a retrospective study of all chronic haemodialysis patients followed by the Southern Alberta Renal Program from January 1, 2005 to June 30, 2008, the incidence of primary failure was $10 \%$ (81 of 831). Demographic and clinical variables and initial intra-access blood flow (IABF) were compared between those with and without loss of primary functional patency. ${ }^{9}$

At the end of the 9-month follow-up period, $62.7 \%$ of the AVF had a successful outcome. $21.2 \%$ became non-functional. In $15.3 \%$ cases, a new fistula was made at another site. One case was lost to follow-up.

Late re-exploration was done for 19 AVFs. Out of these 19 , four of them required creation of new fistula at another site. Three of them remained non-functional even after the reexploration. Ulno basilic interposition graft with saphenous vein was put for one case. Saphenous interposition graft was put for 5 radiocephalic fistulae during their re-exploration. Transposition of brachiocephalic fistulae were done in 6 cases.

$84.74 \%$ of the arteriovenous fistulae made were used successfully for at least 3 months. $69.4 \%$ worked for 6 months and $62.7 \%$ worked successfully for 9 months. Most of the fistulae in the study group were performed by our experienced vascular surgeon.

Chemla's team in London, UK, performed 552 AVFs in 4 years achieving a primary patency rate at 22 months of $80 \%$ in 153 patients with radiocephalic fistulas. 10

12 patients in the study population expired during the study period. 10 of them expired within 1 month of creation of fistula and 2 of them expired after 4 months of creation of the fistula.

In Kalman et al study the primary success rate of 466 patients for 2 years was about $54 \% \pm 4$, while in a study published in the International Journal of Clinical and Experimental Medicine in 2012, the primary patency rate for two and four years were $65 \%$ and $48 \% .^{5}$

\section{CONCLUSION}

The present study was conducted to evaluate the outcome of arteriovenous access for haemodialysis created in the Department of General Surgery in Christian Medical College and Hospital, Ludhiana from the time period from $1^{\text {st }}$ November 2009 to $31^{\text {st }}$ October 2011. A total of 118 arteriovenous fistulae were made in this time period. All fistulae were made by experienced surgeons in the vascular unit of the department using the end to side technique of anastomosis- 
1. $87.3 \%$ AVFs were made in patients with CKD V.

2. The most common co-morbidity was found to be Systemic Hypertension (73.7\%). 43.2\% of the population had Diabetes Mellitus Type 2; 29.7\% had both the diseases co-existing.

3. There was a statistically significant increase in number of late complications of AVF in patients who had Diabetes Mellitus Type 2, Systemic Hypertension and in patients who had both the co-morbidities co-existing ( $\mathrm{p}$ value- 0.000 ).

4. Late complications were also found to be more in patients who had a history of IV cannulation and IJV insertion prior to making of the fistula ( $p$ value- 0.000 ).

5. There was no association of smoking or anaemia with development of late complications in the AVFs.

6. $97.5 \%$ of cases demonstrated a good thrill in the immediate postoperative period, whereas $2.5 \%$ had only a demonstrable pulse.

7. Early re-exploration, i.e. re-exploration before maturation of fistula was required in $12.7 \%$ of cases.

8. The primary failure rate was $4.2 \%$.

9. The average time taken for maturity of the AVF was 4 to 6 weeks.

10. Late re-exploration was required for 19 AVFs. Out of these 19 , four of them required creation of new fistula at another site. Three of them remained non-functional even after the re-exploration. Ulno basilic interposition graft with saphenous vein was put for one case. Saphenous interposition graft was put for 5 radiocephalic fistulae during their re-exploration. Transposition of brachiocephalic fistulae was done in 6 cases.

11. $84.74 \%$ of the AVFs were used successfully for a minimum time period of 1 to 2.9 months. $69.4 \%$ were used for the time period of 3 to 5.9 months and $62.7 \%$ were used for 6 to 9 months.

\section{REFERENCES}

[1] Huijbregts HJ, Blankestijn PJ. Dialysis access-guidelines for current practice. Eur J Vasc Endovasc Surg 2006;31(3):284-7.

[2] Biuckians A, Scott EC, Meier GH, et al. The natural history of autologous fistulas as first-time dialysis access in the KDOQI era. J Vasc Surg 2008;47(2):415-21.

[3] Beigi AA, Sadeghi AM, Khosravi AR, et al. Effects of the arteriovenous fistula on pulmonary artery pressure and cardiac output in patients with chronic renal failure. J Vasc Access 2009;10(3):160-6.

[4] Yu Q, Yu H, Chen S, et al. Distribution and complications of native arteriovenous fistulas in maintenance hemodialysis patients: a single-center study. J Nephrol 2011;24(5):597-603.

[5] Kazemzadeh GH, Modaghegh MHS, Ravari H, et al. Primary patency rate of native AV fistula: long term follow up. Int J Clin Exp Med 2012;5(2):173-8.

[6] Centofanti G, Fujii EY, Cavalcante RN, et al. An experience of vascular access for hemodialysis in Brazil. Int Arch Med 2011;4:16.

[7] Agarwal AK, Patel BM, Haddad NJ. Central vein stenosis: a nephrologist's perspective. Semin Dial 2007;20(1):5362.

[8] Criado E, Marston WA, Jaques PF, et al. Proximal venous outflow obstruction in patients with upper extremity arteriovenous dialysis access. Ann Vasc Surg 1994;8(6):530-5.

[9] Monroy-Cuadros M, Yilmaz S, Salazar-Bañuelos A, et al. Risk factors associated with patency loss of hemodialysis vascular access within 6 months. Clin J Am Soc Nephrol 2010;5(10):1787-92.

[10] Hentschel DM. Vascular access for hemodialysis. Nephrology Rounds 2008;6:1-6. 